\section{Commentary: Earlier intervention for descending aortic aneurysms may prevent rupture, but what about all the dissections?}

\author{
Robert B. Hawkins, MD, MSc, and \\ J. Hunter Mehaffey, MD, MSc
}

Zafar and colleagues present an updated analysis of the natural history of descending thoracic and thoracoabdominal aortic aneurysms. ${ }^{1}$ John Elefteriades' lab has provided the thoracic community with a wealth of understanding regarding aortic aneurysm pathophysiology. Descending aortic aneurysms were previously thought to have different properties than ascending aortopathies, namely a higher growth rate $(0.3 \mathrm{~cm} /$ year vs $0.1 \mathrm{~cm} /$ year $)$ and a larger hinge point ( $7 \mathrm{~cm}$ diameter vs $6 \mathrm{~cm}$ diameter), with a higher rate of rupture. ${ }^{2}$ This analysis includes more than triple the number of patients (907, compared with 230 in the earlier study). ${ }^{3}$ With this increased power, the authors note 2 important updates. First, descending aneurysms grow slightly slower than previously thought, at an average rate of $0.19 \mathrm{~cm} /$ year. Second, a diameter $\geq 6 \mathrm{~cm}$ was associated with a $19 \%$ yearly rate of rupture, dissection, or death. This brings both the growth rate and hinge point more in line with ascending aneurysms. The authors now recommend intervention for a diameter of 5.0 to $5.5 \mathrm{~cm}$ and provide a useful risk table based on the aortic height index.

There are several methodologic points relevant to these findings that also highlight areas requiring further research. First, aneurysm growth is not actually linear, as the authors describe. Instead, the aortic growth rate increases linearly, which equates to an exponential increase in size over time. Figure 1 extrapolates growth rates from the manuscript for visual reference of the exponential increase as it

From the Division of Thoracic and Cardiovascular Surgery, School of Medicine, University of Virginia, Charlottesville, Va.

Disclosures: Authors have nothing to disclose with regard to commercial support.

Received for publication Nov 6, 2019; revisions received Nov 6, 2019; accepted for publication Nov 6, 2019; available ahead of print Nov 27, 2019.

Address for reprints: Robert B. Hawkins, MD, MSc, Department of Thoracic and Cardiovascular Surgery, University of Virginia, P.O. Box 800679, Charlottesville, VA 22908 (E-mail: rbh6x@virginia.edu).

J Thorac Cardiovasc Surg 2021;161:514-5

$0022-5223 / \$ 36.00$

Copyright (C) 2019 by The American Association for Thoracic Surgery

https://doi.org/10.1016/j.jtcvs.2019.11.031

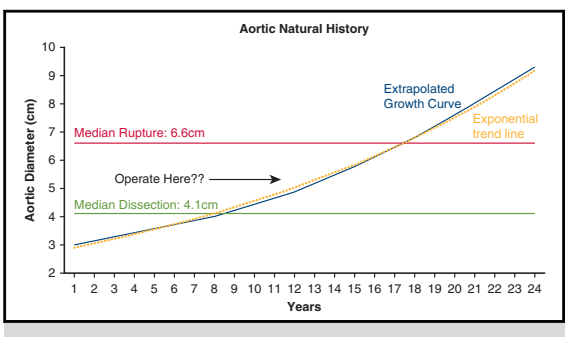

Extrapolated aortic growth and size milestones for dissection, rupture and intervention.

CENTRAL MESSAGE

The risk of aortic rupture in de-

scending aortic aneurysms oc-

curs at smaller diameters than

previously estimated; however,

earlier intervention would have

only limited impact on prevent-

ing dissection.

relates to median dissection and rupture sizes and projected surgical intervention. Because of this, the authors use an instrumental variables approach to account for measurement error and identify risk factors for faster growth. Increasing age, chronic obstructive pulmonary disease, female sex, and nonbovine arch were all associated with faster growth. Should these patients simply undergo more rigorous follow-up, or might there be sex-based differences that warrant different size criteria for intervention, as with abdominal aortic aneurysms? The authors also excluded patients with known connective tissue disorders, in whom the risk of rupture is almost completely unknown.

In addition, although size is a useful criterion for surgical replacement to prevent aortic rupture, it does little to help prevent dissection. In this cohort of patients, $80 \%$ of dissections occurred at $<5 \mathrm{~cm}$, and the median diameter was only $4.1 \mathrm{~cm}$. Although the new growth and rupture characteristics of the descending aortic aneurysm appear more similar to ascending pathology, this is simply not true for dissections, and thus research into nonsurgical prevention methods takes on heightened importance.

Finally, should the size criteria depend on the risk of the intervention? The ability to repair the aneurysm by thoracic endovascular aortic repair, open, and hybrid approaches should dictate the threshold for intervention. ${ }^{4}$ If only there were a risk calculator to determine the precise operative risk, it would be a simple arithmetic. The manuscript is an excellent and welcomed update, but more work is needed 
to provide more complete, evidence-based, patient-specific recommendations.

\section{References}

1. Zafar MA, Chen JF, Wu J, Li Y, Papanikolaou D, Charilaou P, et al. Natural history of descending thoracic and thoracoabdominal aortic aneurysms. J Thorac Cardiovasc Surg. 2021;161:498-511.e1.
2. Elefteriades JA, Farkas EA. Thoracic aortic aneurysm: clinically pertinent controversies and uncertainties. J Am Coll Cardiol. 2010;55:841-57.

3. Coady MA, Rizzo JA, Hammond GL, Kopf GS, Elefteriades JA. Surgical intervention criteria for thoracic aortic aneurysms: a study of growth rates and complications. Ann Thorac Surg. 1999;67:1922-6; discussion 1928-53.

4. Hawkins RB, Mehaffey JH, Narahari AK, Jain A, Ghanta RK, Kron IL, et al. Improved outcomes and value in staged hybrid extent II thoracoabdominal aortic aneurysm repair. J Vasc Surg. 2017;66:1357-63. 